\title{
Expert evidence and the courts 2. Proposals for reform, expert witness bodies and 'the model report'
}

\author{
Keith J. B. Rix
}

In response to what are regarded as the two principal evils of the civil justice system, costs and delay, Lord Woolf, now Master of the Rolls, has presided over an inquiry which has resulted in some proposed reforms which should change radically the administration of civil justice. The implications for experts are best considered against the background of a brief overview of the proposed reforms. This paper then considers the role of the expert witness organisations and the medical version of 'the model expert report'.

\section{Lord Woolf's reforms}

\section{Court-appointed or jointly appointed expert}

The main reform is to transfer responsibility for the conduct of cases from the parties to the court. At present the pace of litigation is dictated by the parties. In order to speed up the litigation and to promote earlier and, in terms of costs, cheaper settlement of cases, there will be a case management conference at an early stage.

As well as defining the issues, and disposing of some summarily, there will be discussion about what issues require expert evidence and what expert evidence should be allowed on each side. It is further proposed that the court will identify issues which can be addressed by a single court-appointed or jointly instructed expert acceptable to both sides, rather than an expert for each side. For example, a single expert may be appointed to deal with straightforward matters of condition and prognosis. In some cases, particularly negligence cases, courtappointed experts may not be appropriate for issues of liability and causation, where the issues may be more contentious, but it is envisaged that they may be appointed sometimes to deal with these issues.

It is likely that, as happens now in child care cases, the court or jointly-appointed expert will receive a set of instructions agreed by all of the parties to the proceedings. Where there is more than one expert it is proposed that defendants will be told the identity of the plaintiff's expert and opposing parties will have the opportunity to instruct the expert before he reports.

\section{Life in the fast lane}

Civil cases will be divided into three groups. The scope of county courts in 'small claims' cases is being increased to claims up to $£ 5000$, but medical experts can expect to have little to do with such cases as the procedure is inappropriate for personal injury cases. However, it is in the county court that experts may pursue solicitors who have failed to settle their accounts!

There will be a 'fast track' for claims in the bracket $£ 5000$ to $£ 15000$. Here it is intended that speed and efficiency will ensure that the costs of justice are proportionate to the size of the claims. For claims worth more than $£ 15000$ and for all medical negligence claims there will be the 'multi-track' where case management may involve a case management conference usually conducted by a procedural judge and a pre-trial review usually conducted by the eventual trial judge. 
The 'fast-track' has three important implications for experts. First, with a set timetable of 20-30 weeks, a long waiting list for the appointment and a lengthy time spent preparing the report will be unacceptable. Second, if more than one expert is instructed, the experts are to be instructed together with a view to their cooperation in the preparation of a joint report indicating areas of agreement and areas of disagreement with the reasons why agreement cannot be reached. If experts meet, it should be unprofessional conduct for an expert to be given or to accept instructions not to reach agreement.

A number of Lord Woolf's proposals relate to the ethical responsibilities of the expert, and their origins in the cases reported in Part 1 of this review (Rix, 1999) can be traced. Reports will be addressed to the court rather than to the party conveying the instructions:

"and experts should be given clear guidance that, when preparing evidence or actually giving evidence to a court, their first responsibility is to the court and not their client".

The report will end with a declaration that it:

"includes everything which the expert regards as being relevant to the opinion which he has expressed in his report and that he has drawn to the attention of the court any matter which would affect the validity of that opinion".

Box 1. The Woolf declaration for use in a civil case

I, Thomas Smeaton, declare that:

1. I understand that my overriding duty in written reports and giving evidence is to help the Court on the matters within my expertise and I have complied with that duty.

2. I have set out in my report what I understand from those instructing me to be the questions in respect of which my opinion as an expert is required.

3. I believe that the facts I have stated in this report are true and that the opinions I have expressed are correct. All of the matters on which I have expressed an opinion lie within my field of expertise.

4. I have drawn the attention of the Court to any matter of which I am aware which may affect the validity of my opinions.

5. Where there is a range of opinion on the matters with which the report deals, $I$ have summarised the range of opinion and given reasons for my opinion.

6. I have stated the substance of all material instructions, whether written or oral, on the basis of which the report is written and $I$ have indicated the sources of all information $I$ have used if based on facts of which I have no personal knowledge.

7. Nothing has been included in the report, or excluded from it, that has been suggested to me by another party without my forming an independent view of it.

8. At the time of signing the report I consider that it is complete, accurate and mentions all matters that I believe are relevant to my expressed opinion. I will notify those instructing me immediately and in writing if, for any reason, my existing report requires any correction or qualification.

9. I understand that:

(a) My report, subject to any corrections before swearing as to its correctness, will form the evidence to be given under oath/upon affirmation;

(b) I may be cross-examined on the report by a cross-examiner assisted by an expert;

(c) I am likely to be the subject of public adverse criticism by the judge if the Court concludes that $I$ have not taken reasonable care in trying to meet the standards set out above.

10. I confirm that I have not entered into any arrangement where the amount or payment of my fees is in any way dependent on the outcome of the case.

11. This report is provided to those instructing me with the sole purpose of assisting the court in this particular case. It may not be used for any other purpose, nor may it be disclosed to any third party, without my express written authority. 
Box 1 shows a specimen 'Woolf declaration'.

With a clear signal to the expert witness organisations and perhaps also to the medical Royal Colleges and Faculties, Lord Woolf has also recommended that:

"Codes of practice providing guidance as to the practice in relation to experts should be drawn up jointly by the appropriate professional bodies representing the experts and the legal profession".

Finally, he has recommended that:

"training courses and published material should provide expert witnesses with a basic understanding of the legal system and their role within it, focusing on the expert's duty to the court, and enable them to present written and oral evidence effectively".

Although Lord Woolf's proposals are for the reform of the civil justice system, a number of his recommendations, as also those of Cresswell $\mathrm{J}$ in the Ikarian Reefer case (National Justice Compania Naviera SA v. Prudential Assurance Co. Ltd "Ikarian Reefer", 1993), are applicable in the criminal courts, the family courts and other tribunals as Bracewell J pointed out in Clough $v$. Tameside \& Glossop Health Authority (1998; Rix, 1999).

\section{Expert witness organisations}

In parallel with the progressive definition of the roles and responsibilities of the expert and partly in response to Lord Woolf's proposals, the past few years have seen a burgeoning of expert witness organisations and the training courses for expert witnesses. The longest established body is the Academy of Experts, which is now more than 10 years old, and potentially the most important is the Expert Witness Institute established under the presidency of Lord Woolf. Also active in the field is the Society of Expert Witnesses. In addition there are two registers of experts: the Law Society Directory of Expert Witnesses and the UK Register of Expert Witnesses.

These organisations produce literature which is very similar to the point of unnecessary duplication. There are several codes of practice, suggested model terms of engagement, and similar articles on the Legal Aid system, how to get paid, conduct of expert meetings and issues of indemnity and negligence.

\section{Academy of Experts}

The Academy was established "to promote the better use of Experts, to ensure that the standard of excellence already achieved is maintained and developed and to facilitate the efficient resolution of disputes". Thus, its role is not limited to the provision of advice to the courts and although it used to be the British Academy of Experts, its aims are to promote the use of the independent expert both in the UK and elsewhere. It is a professional society and an accrediting body.

There are three classes of individual membership: fellow, member and associate. Its committees include a disciplinary committee and a judicial committee. It has its own journal, The Expert, and a newsletter, Update. It has a code of practice which embodies the values and standards associated with the role of the independent expert and to which its members must adhere. Its Judicial Committee has produced 'The model form of expert's report' (Torr, 1998; see below) and is now working on a version more suitable for medical reports. The 'Woolf declaration', which now forms part of it, is in accordance with Lord Woolf's proposals.

So far the Academy is the only body with a membership examination (Box 2). It is a written examination designed:

"to test the knowledge which is an essential underpinning to the work of a competent Expert Witness no matter what his speciality".

Answers to questions must demonstrate the candidates' ability to relate theory to practice by drawing from experience of providing expert opinions.

Box 2. Membership examination of the Academy of Experts

Paper 1

The expert: role and responsibilities

Part 1: The role and duties of an expert witness

Part 2: The legal and professional duties of an expert witness

Paper 2

Practice and procedure

Part 1: Instructions and appointment and the report

Part 2: Pre-trial procedures

Part 3: Court appearance and giving evidence

Paper 3

Law and litigation 


\section{Expert Witness Institute}

The Expert Witness Institute was founded in November 1996, in response to the demands of a number of experts who attended a conference at which Lord Woolf's proposals were discussed. The objective of the Institute is:

"the support of the proper administration of justice and the early resolution of disputes through fair and unbiased expert evidence".

The Royal Society of Medicine and the British Medical Association were founding sponsors. However, the latter has since withdrawn for a number of reasons. One was that the Institute was planning an accreditation system, with an examination system in the longer term. Another concerned the link between the Institute and a particular training organisation offering courses for experts. It appears that the Institute may have more medical members than the Academy.

The Institute produces a newsletter, which includes case notes concerning legal cases and judgments of relevance to experts in general. It has also produced a code of practice and is organising courses and seminars on topics such as 'Basic law for expert witnesses' and 'Experts' meetings'.

\section{Society of Expert Witnesses}

There is also a Society of Expert Witnesses established in the same year as the Institute. The main object of the Society is:

"to promote excellence in all aspects of the service provided by expert witnesses".

It produces a newsletter, Dispatches, and organises meetings.

\section{UK Register of Expert Witnesses}

The UK Register of Expert Witnesses exists in order to provide those who need experts with a means of finding them. A newsletter, Your Witness, is also produced, which is similar in form and content to those of the Institute, the Academy and the Society.

\section{Law Society Directory of Expert Witnesses}

Likewise, the Law Society Directory of Expert Witnesses is published in order to assist lawyers find the right expert. However, it also produces a Code of Practice and subscription to it is a requirement for inclusion. Although the Law Society does not accredit the experts it lists, it operates a more rigorous 'vetting' procedure than the UK Register and it allows experts on its Register to indicate that they have been 'checked' by the Law Society.

\section{The model report}

In 1989 the Lord Chancellor approved the formation of a Judicial Committee of the Academy of Experts consisting of seven senior judges representing the English, Scottish and Northern Irish benches. It has produced a 'Model form of expert's report'. It is intended only as a guideline and is intended to be a 'model' rather than a 'standard'.

Recently, the Academy of Experts has been working on a version which is suitable for use by medical experts, and a medical version of the model form has also been produced by Bond Solon Training.

The Academy has identified four particular hallmarks of a good report (Box 3).

The model proposed by the Academy for medical experts has eight sections including a 'Prognosis and recovery' section which is separate from and follows the 'Opinion' section and it includes the 'Declaration' as a main section. The Bond Solon medical model has four main sections and places the 'Declaration' at the end of the appendices. The following account draws on both versions. There are no substantial differences as far as content is concerned. It is the organisation and layout which differ. Box 4 shows how these models can be adapted to a psychiatric report on an accused person prepared for criminal proceedings.

The report begins with a 'front sheet', which includes the title of the action (e.g. $\mathrm{R} v$. Daniel McNaughton) and other key details such as the subject matter (e.g. psychiatric assessment of the

Box 3. Academy of Experts' four principal hallmarks of a good report

A stand-alone, concise, user-friendly format, expressed in the first person singular by the person whose opinion has been given or who adopts as his own the opinion of others

Text which is arranged in short sentences and paragraphs

Judicious use of appendices

Matters of fact being kept separate from matters of opinion 
defendant), the name, address and reference of those instructing the expert, and the name, address and telephone number of the expert who is writing the report. The second page is a 'contents page' although this may be omitted in the case of a short report, identified by the Academy as seven pages or fewer.

The 'Introduction' section comprises a number of subsections. First, 'The writer' gives the full name, status and specialist field of the expert including, if appropriate, registration with the General Medical Council, specialist recognition under the European Specialist Medical Qualifications Order 1995 and approval under the relevant Mental Health Act. Reference is made here to Appendix 1 which is a more detailed curriculum vitae.

Second, is a subsection giving the 'Source of instructions' in the case. In a criminal case this will usually be the name of the instructing solicitors or court or the particular office of the Crown Prosecution Service.

Third is the 'Summary of the case'. It is a paragraph setting out the brief facts of the case as they are understood to be by the expert at the outset of his investigation. If appropriate, reference may be made here to a brief 'chronology' of the case which is an optional appendix.

Fourth is the 'Summary of conclusions'. It is a summary of the expert's principal conclusions in the case.

Fifth, and optional, is a list of the "The parties involved'. It is not essential, but in a complex criminal case it may assist. It is a list including the accused, other accused persons, witnesses whose statements are in evidence and other key people, showing for each their relationship to the accused person and, if appropriate, to other parties listed.

Sixth, is a subsection 'Medical terms and explanations'. It explains how medical or other technical terms will be identified in the report and it refers to the appendix which is a glossary of such terms.

Seventh, 'Disclosure of interest', is a declaration of any actual or potential conflicts of interest and a disclaimer of any connection with any of the parties, witnesses or advisors; or alternatively an acknowledgment that the defendant (or plaintiff in a civil case) is or has been under the clinical care of the expert.

The 'Issues to be addressed' section sets out exactly the issues which the expert has been asked to address. If an issue falls outside his expertise, it should be mentioned here.

'The Investigation of the facts' is the body of the report. It contains the information upon which the expert's opinions are based. It begins with 'Method of investigation' which usually sets out that the report is based on one or more interviews with and examinations of the subject of the report, perhaps
Box 4. Model form of medical report adapted for a criminal case

\section{Section 1}

Introduction

The writer

Source of instructions

Summary of the case

Summary of conclusions

The parties involved

Medical terms and explanations

Disclosure of interest

\section{Section 2}

Issues to be addressed

\section{Section 3}

Investigation of the facts

Method of investigation

Documents

Background history as given by the defendant

Medical history as given by the defendant $v$. Medical history according to medical records

Defendant's account of the alleged offence(s)

Evidence of witnesses concerning the alleged offence(s)

Psychiatric (mental state) examination

Section 4

Opinion

Appendices

an interview with an informant and study of various documents which have been supplied or obtained. These are listed in full in an appendix.

The subsequent subsections may vary from report to report. They can be used to distinguish between the sources of the various facts so that accepted facts can be distinguished from hypothetical facts or disputed facts which may need to be decided by the court. The subject's own account of their background and medical history may need to be proved in evidence. Likewise, an account from an informant may need to be proved in evidence. The subject's medical history based on medical records has different evidential status. In a criminal case the expert may need to evaluate what the defendant now says about the alleged offence, what he told the police when interviewed and what witnesses have said. This section should end with a subsection on examination findings, often headed 'Psychiatric 
examination'. This differs from the rest of the section in that it comprises facts observed by the expert himor herself rather than facts which he or she is asked to assume.

The last section is the 'Opinion' or 'Conclusion'. So far the report should have been entirely factual; although some of the facts may be contested or require to be proved in evidence, no opinion should have been expressed. Judges have been particularly concerned that matters of fact should be kept separate from matters of opinion. This section, employing sub-headings if appropriate for the various issues addressed, is the expert's opinion on each issue together with the full reasons for reaching the opinion. Repetition of the facts already documented should be avoided as far as possible.

Either here, before the signature of the writer and the date, or as a separately signed appendix the 'Woolf declaration' is included.

The appendices will vary from case to case. Appendix 1, 'Qualifications and experience', is essential. It is a one-page abbreviated curriculum vitae which shows the particular relevance of the expert's qualifications and experience to the case. Appendix 2, 'Documents studied', is a complete list of all of the disclosable documents and records to which the expert has had access. Appendix 3, 'Authorities', is optional. It is a list of papers and chapters considered together with copies of any considered essential for understanding the report. Appendix 4 is a 'Glossary of medical and technical terms' in the report and is essential so that such terms can be understood by its 'lay' readers. Appendix 5 is optional and is a 'Brief chronology of the case'. Appendix 6 is the 'Medical records' if it has been decided that reference to the actual records will be necessary in order to understand the report. Appendix 7, if not already incorporated, is the Woolf 'Declaration' (see Box 1).

Few psychiatrists employ the 'model report', but it has much to commend it. It is a model and not a standard to which slavish adherence is required. To the extent that it assists the court's receipt and understanding of psychiatric opinion, it is to be recommended. It may be based on a model originally developed with the reports of accountants, surveyors, architects and scientists in mind, but it can be adapted to ensure that medical evidence to the courts is presented in a 'judge-friendly' format. It may be a relief to the expert to know that he or she has a friend in court!

\section{STOP PRESS}

Progress on Woolf reforms as at 30 December 1998

(NB. Not all proposed reforms described in this article will be implemented or implemented as envisaged by Lord Woolf)

- From 1 April 1999 most claims worth $£ 5000-15000$ go on 'fast track'

- On 26 April 1999 new Civil Court Rules come into force along with new practice directions

- From a later date pre-action protocols on best practice in instruction and use of experts

- Rule 35 (draft 32) 'Experts and assessors'

- The expert's overriding duty is to the Court

- Reduced need for experts to give oral evidence in 'fast track' cases

- Courts will encourage use of a single jointly instructed expert where appropriate but have powers to appoint a court expert

- Instructions from both/all parties to the single court or joint expert

- Practice direction sets out form and content of expert's report

- Requirement for a 'Woolf declaration' at end of expert's report

- Pre-action protocol likely to include the model form of expert report

- Written questions to experts must be put within 28 days of service of report

- Power of court to direct a discussion between experts

- Experts perceived as biased unlikely to be instructed as single experts

- Possible scope for 'shadow' experts to advise a party on its approach to the single court-appointed or jointly appointed expert

- Full and up-to-date details from expert witness organisations

- Full text of Rules on Lord Chancellor's Department web-site: http://www.open.gov.uk/lcd/civil/ crules/introfritm 


\section{Appendix: Useful addresses}

The Academy of Experts

2 South Square, Gray's Inn, London WC1R 5HP.

Tel: 0171637 0333; Fax: 0171637 1893; e-mail: mail@academy-experts.org; Web-site: http:// www.academy-experts.org

\section{Bond Solon Training}

11 Haymarket, London SW1Y 4BP.

Tel: 0171925 0330; Fax: 0171925 1002; e-mail: witness@bondsolon.bdx.co.uk; Web-site: http:// www.bondsolon.com

\section{The Expert Witness Institute}

Newspaper House, 8-16 Great New Street, London EC4A 3BN.

Tel: 0171583 5454; Fax: 0171583 5450; e-mail: mail@ewi.btinternet.com

The Law Society Directory of Expert Witnesses

Sweet \& Maxwell, 21-27 Lamb's Conduit Street, London WC1N 3NJ.

Tel: 0171420 7500; Fax: 01714207510

\section{UK Register of Expert Witnesses}

JS Publications, PO Box 505, Newmarket, Suffolk CB8 7TF.

Tel: 01638561 590; Fax: 01638560 924; e-mail: yw@jspubs. com; Web-site: http://www.jspubs.com

\section{The Society of Expert Witnesses}

JS Publications, PO Box 505, Newmarket, Suffolk CB87TF.

Tel: 0345023 014; Fax: 01638560 924; e-mail: 100014.1530@compuserve.com

\section{References}

Academy of Experts (1992) Members Handbook: Guidance Notes for Experts. London: Academy of Experts.

Rix, K. J. B. (1999) Expert evidence and the courts: 1. The history of expert evidence. Advances in Psychiatric Treatment, 5, 71-77.

Torr, J. (1998) The model form of medical expert's report. The Expert, Autumn, 24.

Woolf, H. K. (1996) Access to Justice. London: HMSO.
Clough $v$. Tameside \& Glossop Health Authority (1998) Lloyd's Rep Med, 69.

National Justice Compania Naviera SA v. Prudential Assurance Co. Ltd "Ikarian Reefer" (1993) 37 EG, 158.

\section{Multiple choice questions}

1. Under Lord Woolf's proposals for reform of the civil justice system:

a the pace of litigation will be dictated by the parties to the action

b fast-track cases will have a set timetable of 20-30 weeks

c if experts meet, it will be unprofessional conduct for an expert to be given or to accept instructions not to reach agreement

d a note of oral instructions needs to be included in the expert's report

e court-appointed experts may be employed in medical negligence cases.

2. The model form of the expert's report:

a has been developed by Lord Woolf

b should be no more than seven pages in length

c is recommended in civil cases in England and Wales

d includes a curriculum vitae of the expert

e was originally developed with medical experts in mind.

3. The Expert Witness Institute:

a is the oldest of the expert witness organisations

b sets a membership examination

c has produced a code of practice for experts

d was founded with sponsorship from the British Medical Association

e was founded with sponsorship from the Royal Society of Medicine.

MCQ answers

$\begin{array}{llll}\text { 1 } & \text { 2 } & 3 \\ \text { a F } & \text { a F } & \text { a F } \\ \text { b T } & \text { b F } & \text { b F } \\ \text { c T } & \text { c T } & \text { c T } \\ \text { d T } & \text { d T } & \text { d T } \\ \text { e T } & \text { e F } & \text { e T }\end{array}$

